\title{
Comparison between Caffeine and Theophylline Therapy for Apnea of Prematurity
}

Kumi Jeong, M.D., Ho Sung Kim, M.D., Eun Song Song, M.D., Ph.D., and Young Youn Choi, M.D., Ph.D. Department of Pediatrics, Chonnam National University Hospital, Gwangju, Korea

\section{ABSTRACT}

Purpose: Methylxanthines are commonly used to treat apnea of prematurity. Recent studies have reported that caffeine therapy reduces the rate of bronchopulmonary dysplasia (BPD) and improves the rate of survival in preterm infant without neurodevelopmental disabilities. This study was performed to compare the effects on apnea episodes, adverse effects and morbidity between the caffeine and theophylline groups.

Methods: A retrospective study was performed in 143 infants born at less than 33 weeks of gestation and treated with caffeine $(n=54)$ or theophylline $(n=89)$ from 2011 to 2012. The baseline characteristics of mothers and their infants were examined. The number of apnea events before and after treatment, the duration of respiratory support, and the rate of re-intubation were compared. Furthermore, adverse effects, clinical course, and morbidities such as BPD and periventricular leukomalacia were compared before discharge.

Results: There were no significant differences in the baseline characteristics. Theophylline and caffeine appeared to have similar short-term therapeutic advantages on apnea of prematurity in mean apnea rate after first two weeks of treatment. However, there were no statistically significant differences in the duration of respiratory support, rate of re-intubation, clinical course, and morbidity between the two groups. Adverse effects, indicated by feeding intolerance were lower in the caffeine group.

Conclusion: Caffeine was as effective as theophylline in the short-term for reducing apnea in preterm babies and was better tolerated and was easier to administer. A prospective randomized study is needed to confirm the effect of caffeine on the loneterm neurodevelopmental outcome in prematurity.

Key Words: Prematurity, Apnea, Caffeine, Theophylline, Side effects, Morbidity

\section{INTRODUCTION}

Apnea of prematurity (AOP) is a relatively common and troublesome disorder that is
Received: 6 October 2014

Revised: 19 November 2014

Accepted: 27 November 2014

Correspondence to:

Young Youn Choi, M.D., Ph.D.

Department of Pediatrics,

Chonnam National University

Hospital, 42 Jebong-ro, Dong-gu,

Gwangju 501-757, Korea

Tel: +82-62-220-6642

Fax: +82-62-222-6103

E-mail: yychoi@jnu.ac.kr

Copyright(c)

By Korean Society of Neonatology.

All right reserved.

This is an Open-Access article distributed under the terms of the Creative Commons Attribution Non-Commercial License (http://creativecommons.org/licenses/ by-nc/3.0), which permits unrestricted non-commercial use, distribution, and reproduction in any medium, provided the original work is properly cited. 
caused by developmental immaturity of the respiratory control system itself or by many diseases or pathophysiologic states affecting oxygen transport or ventilation in preterm infants ${ }^{1)}$. Although the definition of apnea is inconsistent, this condition has been most widely defined as cessation of breathing for more than 20 seconds, typically accompanied by bradycardia and/or cyanosis $^{2}$. Persistent uncontrolled apnea may be harmful to the developing brain and organs and requires re-intubation and prolonged mechanical ventilation ${ }^{3)}$.

The treatment for apnea varies from supportive care such as gentle tactile stimulation or positional change to invasive treatment such as continuous positive airway pressure (CPAP) or mechanical ventilation. Methylxanthine drugs such as caffeine or theophylline are also used for treating this condition ${ }^{4,5)}$. These drugs increase the central respiratory drive by lowering the threshold of response to hypercapnia as well as enhance contractility of the diaphragm and prevent diaphragmatic fatigue. The precise pharmacologic basis for these actions, which are mediated by an increase in respiratory neural output, is still under investigation. A likely major mechanism of action is through competitive antagonism of adenosine receptors, as adenosine acts as an inhibitory neuroregulator in the central nervous system ${ }^{6-9)}$.

According to the Cochrane Database of Systematic Reviews in $2010^{7}$, caffeine appears to have similar short-term effects on apnea/bradycardia as does theophylline, but caffeine has more therapeutic advantages and lower toxicity than theophylline. In addition, caffeine treatment resulted in an increase in the survival rate without neurodevelopmental disability and a decrease in the morbidity such as bronchopulmonary dysplasia (BPD) in low birth weight infants ${ }^{10-17)}$. Although caffeine is widely used, there is no report on the effects of caffeine therapy in Korea because it has been imported recently. The objective of this study was to compare the therapeutic effects, side effects, and morbidity between the caffeine and theophylline groups.

\section{MATERIALS AND METHODS}

\section{Subjects}

One hundred and seventy-one infants born at less than 33 weeks of gestation were admitted to the neonatal intensive care unit of Chonnam National University Hospital from January 2011 to December 2012. Exclusion criteria for study participation were the presence of congenital anomaly $(n=3)$, neuromuscular disease $(n=2)$, severe intraventricular hemorrhage ( $\geq$ grade III) $(n=8)$, surgical condition $(n=8)$, congenital heart disease $(n=5)$, and death $(\mathrm{n}=2)$. Finally, one hundred forty-three infants (82 males and 61 for females) were enrolled in this study. As caffeine therapy was introduced to our hospital in February 2012, the infants treated with caffeine (February 2012 to December 2012) were compared with the infants treated with theophylline (January 2011 to January 2012) in terms of baseline characteristics, effect on apnea episodes, side effects, and morbidity. This study was approved by the institutional review board of Chonnam National University Hospital, and parental consent form was not obtained as the study consisted of retrospective chart review.

\section{Treatment Regimen}

Both theophylline (Theoclear ${ }^{\circledR}$ ) and caffeine $\left(\right.$ Neocaf $\left.^{\circledR}\right)$ were administered as a therapeutic treatment for AOP. In the theophylline group, a loading dose of 5-7 mg/ $\mathrm{kg}$ of theophylline was administered intravenously for 30 minutes, followed by 1.5-2 $\mathrm{mg} / \mathrm{kg}$ every 8 to 12 hours by either the oral or intravenous route. The purpose was to maintain the therapeutic level at 7 to $12 \mu \mathrm{g} /$ $\mathrm{mL}$ by monitoring once or twice a week at 0.5 to 1 hour after intravenous administration or 1 to 2 hours after oral administration. In the caffeine group, a loading dose of $20 \mathrm{mg} / \mathrm{kg}$ of caffeine was administered intravenously for 30 minutes followed by 5-8 $\mathrm{mg} / \mathrm{kg}$ intravenously once a day every 24 hours. If apnea persisted, another dose of $10 \mathrm{mg} / \mathrm{kg}$ was administered. The maintenance dose was increased by $20 \%$ and the serum drug concentration was not measured. The dosage for intravenous or oral administration of the two drugs was the same, and the drugs were discontinued after the infants reached 34 to 36 weeks of gestation, if apnea events has been absent for 5 to 7 days.

\section{Result Analysis}

We compare the baseline characteristics, the effect on apnea events, adverse effects, and morbidity during admission between the caffeine and theophylline groups. Baseline characteristics for mothers such as age, use of antenatal steroids, placental pathology, and delivery method were investigated. For infants, birth-weight, gestational age, gender, birth place, single or multiple births, Apgar scores at 1 and 5 minutes were examined. The postnatal day on which the initial drug therapy was started and the total duration of the drug therapy, duration of ventilatory support and oxygen therapy, and the re-intubation rate were 
examined. The number of apnea events per day according to each time period such as before treatment, 1 to 3 days, 4 to 7 days, and 8 to 14 days after treatment were assessed.

With respect to adverse effects of drug therapy, feeding difficulties such as residual volume, abdominal distension, vomiting, tachycardia ( $\geq 180$ beats/min), and seizure were investigated. The postnatal day on which initial trophic feeding and full enteral feeding were started, the number of red blood cells (RBC) transfusions, and morbidities such as respiratory distress syndrome (RDS), patent ductus arteriosus (PDA), necrotizing enterocolitis (NEC), BPD, and periventricular leukomalacia (PVL) were assessed. RBC transfusion was performed only when the hematocrit level fell below the assigned value in consideration of the level of respiratory support. While tracheally intubated for mechanical ventilation, infants received an RBC transfusion if their hematocrit levels fell to $<30 \%$ in order to maintain hematocrit at $>40 \%$. While receiving nasal CPAP or supplemental oxygen, their hematocrit levels were kept at $>30 \%$. The number of RBC transfusions were only included if they occurred during theophylline and caffeine therapy.

RDS was diagnosed based on the clinical signs, microbubble test, and chest radiographic findings ${ }^{18}$. PDA was diagnosed based on the clinical signs or symptoms along with chest radiographic findings, and the diagnosis was confirmed by echocardiography ${ }^{19)}$. NEC was diagnosed according to the modified Bell's classification (more than stage II) ${ }^{20}$. The criteria for BPD (for neonates treated with more than $21 \%$ oxygen for at least 28 days) was as follows. The time point of assessment was 36 weeks' postmenstrual age or discharge to home (whichever comes first) for babies born before 32 weeks and 56 days' postnatal age or discharge to home (whichever comes first) for babies born after 32 weeks gestation ${ }^{21}$. PVL was diagnosed when cranial ultrasound showed cystic changes in the periventricular area, or when brain magnetic resonance imaging (MRI) showed lack of white matter myelin, or a relative growth of ventricle and gray matter due to a decreased volume of white matter ${ }^{22}$.

\section{Statistical Method}

Statistical analysis was performed to examine the differences between the caffeine and theophylline groups using SPSS for Windows, version 17.1 (SPSS Inc., Chicago, IL, USA). According to data characteristics, Chi-square test and Student $t$-test were performed. The results were considered to be statistically significant when the $P$-value was less than 0.05 .

\section{RESULTS}

\section{Baseline Characteristics}

Among the total 143 patients, there were 54 patients in the caffeine group (30 males, 24 females) and 89 patients in the theophylline group ( 52 males, 37 females). There were no significant differences in maternal age, use of antenatal steroids, presence of histologic chorioamnionitis, and C-section rate between the two groups. Furthermore, neonatal birth weight, gestational age, gender, birth place, single or multiple births, and Apgar scores at 1 and 5 minutes showed no significant differences between the two groups (Table 1).

\section{Therapeutic Effects}

The initial day of therapy was $3.5 \pm 2.8$ days of life in the caffeine group and $2.7 \pm 7.9$ days in the theophylline group, with no stastically significant difference between the two groups. The total duration of treatment was $30.0 \pm 17.4$ days in the caffeine group and $29.7 \pm 10.1$ days in the theophylline group, with no difference between the two groups. With respect to the therapeutic effects according to each time period, the number of apnea events per day was $4.0 \pm 3.2$ before treatment and it was significantly decreased to $2.3 \pm 2.1$ ( $P=0.001), 1.9 \pm 2.0(P<0.001)$, and $1.3 \pm 1.6(P<0.001)$ after 1 to 3 days, 4 to 7 days, and 8 to 14 days of treatment, respectively in the caffeine group. Also, the

Table 1. Baseline Characteristics of Mothers and Their Newborn Infants

\begin{tabular}{lccc}
\hline Characteristics & $\begin{array}{c}\text { Caffeine } \\
\text { group } \\
(\mathrm{n}=54)\end{array}$ & $\begin{array}{c}\text { Theophylline } \\
\text { group } \\
(\mathrm{n}=89)\end{array}$ & $\begin{array}{c}P \text { - } \\
\text { value }\end{array}$ \\
\hline Maternal & $32.3 \pm 3.8$ & $30.9 \pm 0.5$ & 0.16 \\
Age (yr) & $35(66)$ & $54(61)$ & 0.88 \\
Use of antenatal corticosteroids & $25(47)$ & $38(43)$ & 0.61 \\
Histologic chorioamnionitis & $38(72)$ & $61(69)$ & 0.69 \\
Cesarean section & & & \\
Neonatal & $1,353 \pm 280$ & $1,394 \pm 313$ & 0.43 \\
Birth weight (g) & $29.2 \pm 1.6$ & $29.6 \pm 1.7$ & 0.18 \\
Gestational weeks & $24(44)$ & $37(42)$ & 0.67 \\
Female & $43(80)$ & $80(90)$ & 0.17 \\
Inborn & $36(67)$ & $73(82)$ & 0.12 \\
Singleton birth & $7.4 \pm 0.5$ & $5.0 \pm 0.4$ & 0.56 \\
1-minute Apgar score & $7.0 \pm 2.8$ & $4.8 \pm 2.8$ & 0.92 \\
5-minute Apgar score & &
\end{tabular}

Values are expressed as mean \pm SD or number (\%) of individuals. 
number of apnea events per day was $4.0 \pm 3.3$ before treatment and it was significantly decreased to $2.4 \pm 9.6$ ( $P=0.006), 1.4 \pm 2.4$ $(P=0.001)$, and $1.4 \pm 2.8(P<0.001)$ after 1 to 3 days, 4 to 7 days, and 8 to 14 days of treatment, respectively in the theophylline group. However, there were no significant differences between the two groups at each time period (Table 2).

With respect to assisted respiratory therapy, the duration of nasal CPAP (1.9 \pm 3.3 days in the caffeine group vs. $3.5 \pm 2.1$ days in the theophylline group, $P=0.08)$, mechanical ventilation ( $4.6 \pm 5.3$ days vs. 3.6 \pm 7.2 days, $P=0.29$ ) and oxygen supplementation (15.2 \pm 13.9 days vs. $14.3 \pm 6.0$ days, $P=0.74$ ), and the rate of re-intubation ( $22.6 \%$ vs. $19.1 \%, P=0.67)$ were not significantly different between the two groups (Table 2).

\section{Adverse Effects}

The percentage of patients who experienced feeding difficulties such as residual volume (more than half of the feeding amount), abdominal distention, regurgitation, or vomiting was $90.6 \%$ in the caffeine group and $98.9 \%$ in the theophylline group with a statistical significance $(P=0.027)$. The number of episodes of feeding difficulties per patient during drug therapy was $8.4 \pm$

Table 2. Drug Therapy and Effect on Apnea and Respiratory Support

\begin{tabular}{lccc}
\hline & $\begin{array}{c}\text { Caffeine } \\
\text { group } \\
(\mathrm{n}=54)\end{array}$ & $\begin{array}{c}\text { Theophylline } \\
\text { group } \\
(\mathrm{n}=89)\end{array}$ & $\begin{array}{c}P \text { - } \\
\text { value }\end{array}$ \\
\hline $\begin{array}{l}\text { Drug therapy } \\
\text { Initial day of therapy }\end{array}$ & $3.5 \pm 2.8$ & $2.7 \pm 7.9$ & 0.11 \\
Total days & $30.0 \pm 17.4$ & $29.7 \pm 10.1$ & 0.91 \\
Apnea events/day & & & \\
Before therapy & $4.0 \pm 3.2$ & $4.0 \pm 3.3$ & 1.00 \\
After 1-3 days & $2.3 \pm 2.1^{*}$ & $2.4 \pm 9.6^{\S}$ & 0.84 \\
$\quad$ 4-7 days & $1.9 \pm 2.0^{\dagger}$ & $1.4 \pm 2.4$ & 0.23 \\
$\quad$ 8-14 days & $1.3 \pm 1.6^{\dagger}$ & $1.4 \pm 2.8^{\complement}$ & 0.73 \\
Respiratory support days & & & \\
Nasal continuous positive & $1.9 \pm 3.3$ & $3.5 \pm 2.1$ & 0.08 \\
$\quad$ airway pressure & & & \\
Mechanical ventilation & $4.6 \pm 5.3$ & $3.6 \pm 7.2$ & 0.29 \\
Total oxygen supply & $15.2 \pm 13.9$ & $14.3 \pm 6.0$ & 0.74 \\
Re-intubation & $12(22.6)$ & $17(19.1)$ & 0.67 \\
\hline
\end{tabular}

Values are expressed as mean \pm SD or number (\%) of individuals. Compared to before the initiation of therapy, apnea events were significantly decreased after 1 to 3 days, 4 to 7 days, and 8 to 14 days of therapy in both the caffeine $\left(P=0.001^{*}, P<0.001^{\dagger}, P<0.001^{\ddagger}\right.$, respectively) and theophylline groups $\left(P=0.006^{\S}, P=0.001, P<0.001^{\uparrow}\right.$, respectively).
6.7 in the caffeine group compared with $11.9 \pm 0.6$ in the theophylline group with a statistical significance $(P=0.042)$. Tachycardia ( $\geq 180$ beats $/ \mathrm{min}$ ) was noted in $47.2 \%$ of patients in the caffeine group and in $50.6 \%$ of patients in the theophylline group with no significance. The number of tachycardia events per patient during drug therapy was $1.8 \pm 4.0$ in the caffeine group and 2.6 \pm 9.4 in the theophylline group with no significance. Neurologic abnormality such as seizure was not noted in the caffeine group, but three patients in the theophylline group developed a neurologic abnormality; however, this result was not statistically significant (Table 3).

\section{Clinical Course and Morbidity}

The initial trophic feeding was started on $2.9 \pm 1.5$ postnatal days in the caffeine group and on $2.6 \pm 9.0$ postnatal days in the theophylline group, but it showed no statistical significance $(P=$ 0.35). Furthermoreo, there was no difference in the postnatal day on which total enteral feeding was started (26.1 \pm 9.9 days in the caffeine group and 26.4 \pm 1.6 days in the theophylline group, $P=0.83)$. For the treatment of AOP, RBC transfusions were performed in 26 patients (48.1\%) of the caffeine group and in 27 patients (30.3\%) of the theophylline group with no significance. During the hospitalization period, there were no significant differences in morbidities such as RDS, PDA, NEC, BPD, and PVL between the two groups (Table 4).

\section{DISCUSSION}

Newborns especially the extremely premature babies encounter problems with body temperature regulation, acquisition of proper feeding, and control of respiration within the first few days of life ${ }^{23)}$. Although the exact mechanism is not entirely clear,

Table 3. Incidence of Side Effects and Number of Events per Patient

\begin{tabular}{lccc}
\hline & $\begin{array}{c}\text { Caffeine } \\
\text { group } \\
(\mathrm{n}=54)\end{array}$ & $\begin{array}{c}\text { Theophylline } \\
\text { group } \\
(\mathrm{n}=89)\end{array}$ & $\begin{array}{c}P \text { - } \\
\text { value }\end{array}$ \\
\hline Feeding intolerance & $48(90.6)$ & $88(98.9)$ & 0.027 \\
Events per patient & $8.4 \pm 6.7(48)$ & $11.9 \pm 0.6$ & 0.042 \\
Tachycardia & $25(47.2)$ & $45(50.6)$ & 0.731 \\
Events per patient & $1.8 \pm 4.0(25)$ & $2.6 \pm 9.4(45)$ & 0.388 \\
Seizure & $0(0.0)$ & $3(3.4)$ & 0.083
\end{tabular}

Values are expressed as mean \pm SD or number (\%) of individuals. 
Table 4. Clinical Course and Morbidity

\begin{tabular}{lccc}
\hline & $\begin{array}{c}\text { Caffeine } \\
\text { group } \\
(\mathrm{n}=54)\end{array}$ & $\begin{array}{c}\text { Theophylline } \\
\text { group } \\
(\mathrm{n}=89)\end{array}$ & $\begin{array}{c}P \text { - } \\
\text { value }\end{array}$ \\
\hline Enteral feeding (postnatal days) & & & \\
$\quad$ Initial trophic & $2.9 \pm 1.5$ & $2.6 \pm 9.0$ & 0.35 \\
Full oral & $26.1 \pm 9.9$ & $26.4 \pm 1.6$ & 0.83 \\
Red blood cells transfusion & $26(48.1)$ & $27(30.3)$ & 0.10 \\
Respiratory distress syndrome & $37(69.8)$ & $72(80.9)$ & 0.20 \\
Patent ductus arteriosus & $26(49.1)$ & $40(44.9)$ & 0.22 \\
Necrotizing enterocolitis & $7(13.2)$ & $11(12.4)$ & 0.88 \\
Bronchopulmonary dysplasia & $14(25.9)$ & $18(20.2)$ & 0.39 \\
Periventricular leukomalacia & $5(9.3)$ & $7(7.9)$ & 0.75
\end{tabular}

Values are expressed as mean \pm SD or number (\%) of individuals

developmental immaturity of central respiratory drive is a likely contributing factor, since apneic spells occur more frequently in immature infants. Also, decreased chemoreceptor response to hypoxia and hypercapnia, active reflexes invoked by stimulation of the posterior pharynx, and ineffective ventilation due to impaired coordination of the inspiratory muscles and the muscles of the upper airway may play a role ${ }^{24,25)}$.

The incidence of AOP increases with decreasing gestational age or birth weight. The younger the gestational weeks, the incidence is more prevalent; $7 \%$ at 34 to 35 weeks of gestation, $15 \%$ at 32 to 33 weeks of gestation, and $54 \%$ at 30 to 31 weeks of gestation. Essentially, all infants less than 28 weeks of gestational age or less than 1,000 g of birth weight have AOP ${ }^{5,23}$. Persistent apnea may be harmful to the developing brain or organs. Methylxanthines (such as caffeine and theophylline) are drugs that are believed to stimulate breathing and have been used to reduce apnea.

In the Cochrane review in 2010, Henderson-Smart and Steer ${ }^{7)}$ reported that there was no difference in mean apnea rate between the caffeine and theophylline groups after one to three days treatment and five to seven days treatment. No difference in treatment failure rate (less than $50 \%$ reduction in apnea/ bradycardia) was found between the caffeine and theophylline groups after one to three days treatment or five to seven days treatment. In our study, there was no difference in the baseline characteristics of mothers and their newborn infants, and the initial day and total duration of drug therapy between the two groups. Compared to before treatment, daily mean apnea rate was significantly decreased until 14 days after treatment in both groups, and there was no difference between the two groups, which was similar to that in a previous report ${ }^{7)}$.

Side effects of methylxanthines which lead to changes in doses include tachycardia and signs of gastrointestinal dysfunction, including abdominal distention, feeding intolerance, or vomiting. jitteriness, irritability, and seizures may also be seen. In very low birth weight infants, mild diuresis and urinary calcium excretion occur ${ }^{26-28)}$. In the Cochrane review in 2010 ${ }^{7}$, adverse effects were lower in the caffeine group (summary relative risk 0.17 , 95\% CI 0.04 to 0.72 ), and theophylline was associated with higher rates of toxicity. Caffeine has several advantages such as effects similar to those of theophylline on apnea, lesser adverse effects, larger gap between therapeutic and toxic levels, more easy absorption, and longer half-life that allows once-daily dosing ${ }^{7)}$.

In our study, the caffeine group showed a significantly less feeding intolerance than the theophylline group, but there was no significant difference in the postnatal day on which initial trophic feeding and full enteral feeding were started. With respect to neurological problems, seizure was observed in three patients of the theophylline group and in none of the patients of the caffeine group, but this difference was not statistically significant. It could not be confirmed that the seizure was related to theophylline therapy because the serum theophylline concentrations in all three patients with seizure were within their therapeutic ranges.

It is controversial whether $\mathrm{RBC}$ transfusion reduces the frequency of apneic spells in some infants. In a randomized trial, Bell et al. ${ }^{29)}$ reported that apnea occurred more frequently in the group with limited transfusions. In this study, packed RBC transfusion was considered if the hemoglobin level was less than $10 \mathrm{~g} / \mathrm{dL}$ or if the hematocrit was less than $30 \%$ and the infant had frequent or severe episodes of apnea and bradycardia while respiratory support. There was no significant difference in the number of RBC transfusions between the two groups.

Schmidt et al. ${ }^{16)}$ conducted a randomized study in preterm infants with birth weight from 500 to $1,250 \mathrm{~g}$ during the first 10 days of life and they received either caffeine or placebo; the authors evaluated the short-term outcomes before the preterm infants were discharge home. In the caffeine treatment group, positive airway pressure was discontinued about 1 week earlier than that in the placebo group (31.0 weeks vs. 32.0 weeks, $P<$ 0.001). Also, among the infants who remained alive at a postmenstrual age of 36 weeks, the need for oxygen therapy was less in the caffeine group ( $36 \%$ vs. $47 \%, P<0.001)$. The cranial ultra- 
sonographic findings and frequency of NEC did not differ between the two groups. Weight gain was reduced temporarily in the caffeine group, and the difference was significant especially at two weeks after birth. Also, the frequency of PDA that required medical treatment $(29.3 \%$ vs. $38.1 \%, P<0.001)$, especially surgical treatment ( $4.5 \%$ vs. $12.6 \%, P<0.001$ ) was less in the caffeine group. Our study was a not a placebo-controlled study, but it was a comparative study between the caffeine and theophylline groups. There were no differences in the duration of assisted respiratory support, the rate of re-intubation, and the incidence of PDA, PVL, and BPD during hospitalization between the two groups.

Also, Schmidt et al. ${ }^{17)}$ studied the long-term effects of caffeine therapy on AOP in infants with birth weights of 500 to $1,250 \mathrm{~g}$ at a corrected age of 18 to 21 months. The infants treated with caffeine showed reduced incidences of cerebral palsy ( $4.4 \%$ vs. $7.3 \%, P=0.009)$ and cognitive delay (33.8\% vs. $38.3 \%, P=0.04)$ compared to the placebo group. The rates of death, deafness, and blindness, and the mean percentiles for height, weight, and head circumference at follow-up did not differ significantly between the two groups. There was no significant difference in the incidence of PVL for predicting the neurodevelopmental outcome between the two groups in our study, and therefore, a more long-term post-discharge follow-up is needed to assess the neurodevelopmental outcome.

Caffeine is more expensive than theophylline. But it can be used once a day because of its longer half life and does not require periodic monitoring because of its broad therapeutic range ${ }^{12,13,30)}$. In addition, it reduces the burden of blood sampling and the cost for drug monitoring. Although this is the first comparative study between caffeine and theophylline therapies for AOP in our country, the limitation of this study is that it was a single center retrospective study and the time period was different for the two regimens.

In conclusion, both caffeine and theophylline showed similar effects on apnea events. Caffeine has several advantages such as less feeding intolerance, once a day treatment, no need of drug monitoring, and cost effectiveness. For clarifying its drug effect on long-term neurodevelopmental morbidity such as cerebral palsy, a prospective, multi-center, randomized controlled study comparing each of the two methylxanthines (caffeine or theophylline) with placebo or caffeine versus theophylline is needed.

\section{REFERENCES}

1) Darnall RA, Ariagno RL, Kinney HC. The late preterm infant and the control of breathing, sleep, and brainstem development: a review. Clin Perinatol 2006;33:883-914.

2) Committee on Fetus and Newborn. American Academy of Pediatrics. Apnea, sudden infant death syndrome, and home monitoring. Pediatrics 2003;111:914-7.

3) Bauschatz AS, Kaufmann CM, Haensse D, Pfister R, Bucher HU. A preliminary report of nursing in the three-stair-position to prevent apnoea of prematurity. Acta Paediatr 2008;97:17435.

4) Clark RH, Bloom BT, Spitzer AR, Gerstmann DR. Reported medication use in the neonatal intensive care unit: data from a large national data set. Pediatrics 2006;117:1979-87.

5) Martin RJ, Abu-Shaweesh JM, Baird TM. Apnoea of prematurity. Paediatr Respir Rev 2004;5 Suppl A:377-82.

6) Aranda JV, Beharry K, Valencia GB, Natarajan G, Davis J. Caffeine impact on neonatal morbidities. J Matern Fetal Neonatal Med 2010;23 Suppl 3:20-3.

7) Henderson-Smart DJ, Steer PA. Caffeine versus theophylline for apnea in preterm infants. Cochrane Database Syst Rev 2010:CD000273. doi:10.1002/14651858.CD000273.pub2.

8) Mueni E, Opiyo N, English M. Caffeine for the management of apnea in preterm infants. Int Health 2009;1:190-5.

9) Henderson-Smart DJ, Steer P. Methylxanthine treatment for apnea in preterm infants. Cochrane Database Syst Rev 2001: CD000140. doi:10.1002/14651858.CD000140.pub2.

10) Lee TC, Charles B, Steer P, Flenady V, Shearman A. Population pharmacokinetics of intravenous caffeine in neonates with apnea of prematurity. Clin Pharmacol Ther 1997;61:628-40.

11) Scanlon JE, Chin KC, Morgan ME, Durbin GM, Hale KA, Brown SS. Caffeine or theophylline for neonatal apnoea? Arch Dis Child 1992;67:425-8.

12) Aranda JV, Turmen T. Methylxanthines in apnea of prematurity. Clin Perinatol 1979;6:87-108.

13) Natarajan G, Botica ML, Thomas R, Aranda JV. Therapeutic drug monitoring for caffeine in preterm neonates: an unnecessary exercise? Pediatrics 2007;119:936-40.

14) Leon AE, Michienzi K, Ma CX, Hutchison AA. Serum caffeine concentrations in preterm neonates. Am J Perinatol 2007;24: 39-47.

15) Aranda JV, Cook CE, Gorman W, Collinge JM, Loughnan PM, Outerbridge EW, et al. Pharmacokinetic profile of caffeine in the premature newborn infant with apnea. J Pediatr 1979;94: 663-8.

16) Schmidt B, Roberts RS, Davis P, Doyle LW, Barrington KJ, Ohlsson A, et al. Caffeine therapy for apnea of prematurity. N Engl J Med 2006;354:2112-21. 
17) Schmidt B, Roberts RS, Davis P, Doyle LW, Barrington KJ, Ohlsson A, et al. Long-term effects of caffeine therapy for apnea of prematurity. N Engl J Med 2007;357:1893-902.

18) Bomsel F. Radiologic study of hyaline membrane disease: 110 cases. J Radiol Electrol Med Nucl 1970;51:259-68.

19) Yeh TF, Luken JA, Thalji A, Raval D, Carr I, Pildes RS. Intravenous indomethacin therapy in premature infants with persistent ductus arteriosus--a double-blind controlled study. J Pediatr 1981;98:137-45.

20) Walsh MC, Kliegman RM, Fanaroff AA. Necrotizing enterocolitis: a practitioner's perspective. Pediatr Rev 1988;9:219-26.

21) Jobe AH, Bancalari E. Bronchopulmonary dysplasia. Am J Respir Crit Care Med 2001;163:1723-9.

22 Flodmark O, Roland EH, Hill A, Whitfield MF. Periventricular leukomalacia: radiologic diagnosis. Radiology 1987;162:11924.

23) Stokowski LA. A primer on apnea of prematurity. Adv Neonatal Care 2005;5:155-70; quiz 71-4.

24) Darnall RA. The role of $\mathrm{CO}_{2}$ and central chemoreception in the control of breathing in the fetus and the neonate. Respir
Physiol Neurobiol 2010;173:201-12.

25) Praud JP. Upper airway reflexes in response to gastric reflux. Paediatr Respir Rev 2010;11:208-12.

26) Adén U. Methylxanthines during pregnancy and early postnatal life. Handb Exp Pharmacol 2011;200:373-89.

27) Carnielli VP, Verlato G, Benini F, Rossi K, Cavedagni M, Filippone $\mathrm{M}$, et al. Metabolic and respiratory effects of theophylline in the preterm infant. Arch Dis Child Fetal Neonatal Ed 2000;83:F39-43.

28) Skopnik H, Koch G, Heimann G. Effect of methylxanthines on periodic respiration and acid gastroesophageal reflux in newborn infants. Monatsschr Kinderheilkd 1990;138:123-7.

29) Bell EF, Strauss RG, Widness JA, Mahoney LT, Mock DM, Seward VJ, et al. Randomized trial of liberal versus restrictive guidelines for red blood cell transfusion in preterm infants. Pediatrics 2005;115:1685-91.

30) Jones RA, Baillie E. Dosage schedule for intravenous aminophylline in apnoea of prematurity, based on pharmacokinetic studies. Arch Dis Child 1979;54:190-3. 